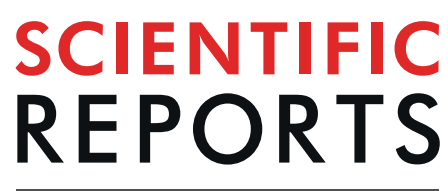

natureresearch

\title{
Photocatalytic Degradation of Organic Pollutants over $\mathrm{MFe}_{2} \mathrm{O}_{4}$ $(\mathrm{M}=\mathrm{Co}, \mathrm{Ni}, \mathrm{Cu}, \mathrm{Zn})$ Nanoparticles at Neutral pH
}

\author{
Nishesh Kumar Gupta ${ }^{1,2}$, Yasaman Ghaffari ${ }^{1,2}$, Suho Kim ${ }^{1,2}$, Jiyeol Bae ${ }^{2}$, Kwang Soo Kim ${ }^{1,2 *}$ \& \\ Md Saifuddin ${ }^{1,2}$
}

In this study, we report a surfactant-mediated synthesis of ferrites $\left(\mathrm{MFe}_{2} \mathrm{O}_{4}: \mathrm{M}=\mathrm{Co}, \mathrm{Ni}, \mathrm{Cu}, \mathrm{Zn}\right.$ ) using the co-precipitation-oxidation method. The band gap calculated from UV-Visible diffuse reflectance spectra were found in the range of 1.11-1.81 eV. These ferrite nanocatalysts were studied for the photocatalytic degradation of multiple organic dyes in a $32 \mathrm{~W} \mathrm{UV}-\mathrm{C} / \mathrm{H}_{2} \mathrm{O}_{2}$ system. All the four ferrites showed an excellent dye degradation rate in the range of $2.065-2.417 \mathrm{~min}^{-1}$ at neutral $\mathrm{pH}$. In the optimized condition, $\mathrm{NiF}$ was found to degrade $89 \%, 92 \%, 93 \%$, and $78 \%$ of methylene blue, methyl orange, bromo green, and methyl red, respectively within 1 min of UV-irradiation. A 40\% TOC removal was recorded after $5 \mathrm{~min}$ of degradation reaction, which increased to $60 \%$ after $50 \mathrm{~min}$. Mechanism elucidated by scavenger studies and fluorescence spectroscopy revealed that ${ }^{\circ} \mathrm{OH}$ and holes were the primary reactive radicals responsible for the degradation process. Ferrite photocatalysts showed an insignificant performance loss in seven consecutive cycles. The photocatalyst was found efficient in the presence of a high concentration of salts. Thus, it was concluded that these photocatalysts are highly suitable for the remediation of dye-contaminated wastewater.

The ever-increasing population, coupled with rapid urbanization and industrialization, have deteriorated the quality of life. Excessive contamination of water bodies could be a severe threat to both human beings and other life forms. Organic dyes are considered as one of the major pollutants discharged into the environment by textile, printing, food, and leather industries ${ }^{1}$. Though a large segment of these synthetic dyes is non-toxic or less toxic, their presence in water increases the oxygen demand, which in turn affects aquatic animals ${ }^{2}$. Among the dyes consumed in industries, up to $70 \%$ belong to azo dye family (those with azo-functional group " $-\mathrm{N}=\mathrm{N}-$ ”). Azo dyes have genotoxic, mutagenic, and carcinogenic effects on living beings ${ }^{3}$. Some of the azo dyes are known to be carcinogenic in the non-cleaved state, and for many of the azo dyes, their cleaved products such as benzidine are known to induce tumors ${ }^{4}$. Conventional biological, chemical, and physical methods like adsorption ${ }^{5,6}$, chemical precipitation ${ }^{7}$, and microbial degradation ${ }^{8}$ have been established for the remediation of dye-contaminated wastewater. The practical application of these processes suffers due to high operational cost, sludge production, or formation of secondary pollutants. For a complete or partial degradation of organic dyes (into non-toxic byproducts), degradation by adopting the photocatalytic process is one of the viable options.

In recent years, advanced oxidation processes based on the generation of highly reactive hydroxyl radicals have gained momentum for the degradation of toxic organic pollutants ${ }^{9}$. Though the Fenton process is easier to operate, it suffers badly due to a slow regeneration of $\mathrm{Fe}^{2+}$ ions ${ }^{10}$. Thus, the ultraviolet radiation or electrochemical method is generally coupled with the Fenton process for the regeneration of $\mathrm{Fe}^{2+}$ ions ${ }^{10,11}$. Unfortunately, the homogeneous photo-Fenton process has two significant drawbacks, i.e., a narrow operational $\mathrm{pH}$ range and formation of sludge, which increase the overall cost of the process ${ }^{12}$. These drawbacks are motivating researchers to develop cost-effective UV-light responsive heterogeneous photocatalysts.

Among numerous metal-oxide based photocatalysts developed, researchers are fixated on spinel ferrites due to their narrow band gap, magnetic property, and high stability ${ }^{13}$. Moreover, the magnetic and optical properties

${ }^{1}$ University of Science and Technology (UST), Daejeon, Republic of Korea. ${ }^{2}$ Department of Land, Water, and Environment Research, Korea Institute of Civil Engineering and Building Technology (KICT), Goyang, Republic of Korea. *email: kskim@kict.re.kr 
of $\mathrm{Fe}_{3} \mathrm{O}_{4}$ (simplest ferrite) could be easily tuned by replacing $\mathrm{Fe}^{2+}$ ions with other divalent cations ( $\mathrm{Mn}, \mathrm{Co}$, $\mathrm{Ni}, \mathrm{Cu}, \mathrm{Zn}, \mathrm{Ca}$, and $\mathrm{Mg})^{14}$. Many researchers have exploited ferrite photocatalysts for the photocatalytic degradation of organic pollutants. Cai et al., 2016 developed $\mathrm{ZnFe}_{2} \mathrm{O}_{4}$ via a reduction-oxidation method, which showed decolorization of Orange II dye in visible light/catalyst $/ \mathrm{H}_{2} \mathrm{O}_{2}$ system ${ }^{15}$. Sharma et al., 2014 synthesized $\mathrm{MFe}_{2} \mathrm{O}_{4}(\mathrm{M}=\mathrm{Co}, \mathrm{Ni}, \mathrm{Cu}, \mathrm{Zn})$ by sol-gel method and studied the degradation of methylene blue at pH 2.5 in visible light/catalyst $/ \mathrm{H}_{2} \mathrm{O}_{2}$ system ${ }^{16}$. Dhiman et al., 2016 reported visible light-assisted photocatalytic degradation of safranine- $\mathrm{O}$ and remazol brilliant yellow at $\mathrm{pH} 2.5$ onto morphologically different $\mathrm{NiFe}_{2} \mathrm{O}_{4}$ synthesized by hydrothermal route ${ }^{17}$. Though these studies showed remarkable visible-light-driven photocatalytic degradation of organic dyes, significant issues with these research works were low $\mathrm{pH}$ requirement, slow degradation kinetics, and high energy consumption.

Considering these drawbacks as challenges, we focused on the development of novel ferrite photocatalysts, which could be used for dye degradation at neutral $\mathrm{pH}$ with low energy consumption. We successfully developed an economical and robust surfactant-mediated co-precipitation method for the fabrication of spinel ferrites $\left(\mathrm{MFe}_{2} \mathrm{O}_{4} ; \mathrm{M}=\mathrm{Co}, \mathrm{Ni}, \mathrm{Cu}, \mathrm{Zn}\right)$. The prepared photocatalysts were characterized by various microscopic and spectroscopic techniques for understanding the structural, functional, and optical properties. These ferrite photocatalysts were found highly efficient in degrading multiple organic dyes at neutral $\mathrm{pH}$ in a $32 \mathrm{~W} \mathrm{UV}-\mathrm{C} / \mathrm{H}_{2} \mathrm{O}_{2}$ system. The kinetic rates observed in the present study were the highest ever reported under these sets of experimental conditions. Furthermore, the dye degradation mechanism was deduced based on the scavenger studies and fluorescence spectroscopy.

\section{Results and discussions}

Characterization of ferrite photocatalysts. The morphology of ferrite photocatalysts was characterized by scanning electron microscopy (SEM), and results have been shown in Supplementary Fig. 1. SEM micrographs of all the four photocatalysts, i.e., $\mathrm{CoF}, \mathrm{NiF}, \mathrm{CuF}$, and $\mathrm{ZnF}$ showed a coral-like morphology. EDS analysis of CoF photocatalyst has been shown in Supplementary Fig. 2. From the EDS spectrum in Supplementary Fig. 2(a), Fe, $\mathrm{Co}$, and $\mathrm{O}$ were observed at their corresponding keV values. The peaks of Pt observed in the EDS spectrum were due to the coating at the time of SEM analysis for better visibility of the surface morphology. The 2D elemental mappings showed a uniform distribution of constituent elements in CoF, thus confirming the homogeneity of the photocatalyst (Supplementary Fig. 2(b)).

The morphology of ferrites was further investigated by high-resolution transmission electron microscopy (HRTEM). Single crystals were observed for all the four ferrites (Supplementary Fig. 3). The crystallite planes were assigned by measuring the fringe width values on the HRTEM image and then correlating it with the interplanar spacing $(d)$ values from the XRD pattern. The fringe width of $0.48 \mathrm{~nm}$ corresponding to the (111) plane was observed for both $\mathrm{CoF}$ and $\mathrm{NiF}$ ferrites. The same fringe width was also observed for CuF, but it was assigned to the (101) plane of the tetragonal crystal system. For ZnF, the two fringes width, $0.299 \mathrm{~nm}(220)$, and $0.162 \mathrm{~nm}$ (511) were distinctly visible (Fig. 1).

Porosity properties and specific surface area of ferrite nanoparticles were analyzed by $\mathrm{N}_{2}$ adsorption-desorption isotherm (Supplementary Fig. 4). All the four ferrites showed a similar hysteresis loop at a high relative pressure fit for type IV of adsorption isotherm corresponding to the mesoporous materials ${ }^{18}$. The hysteresis loop at a high relative pressure $\left(P / P_{0}\right)$ in the range of $0.5-1.0$ showed that the mesopores are irregular in the photocatalyst which was further confirmed by the Barrett, Joyner, and Halenda pore size distribution (inset images in Supplementary Fig. 4). The three photocatalysts, i.e., CoF, NiF, and CuF, showed a broader pore size in the range of 3-250 $\mathrm{nm}$. In contrast, for $\mathrm{ZnF}$, pore size in the range of $3-60 \mathrm{~nm}$ with a narrow peak centered at $\sim 35 \mathrm{~nm}$ showed non-uniform sizes and shapes of the nanopores from the agglomeration of ferrite nanoparticles. The method for calculating total surface area $\left(S_{\text {tot }}\right)$ and BET surface area $\left(S_{\mathrm{BET}}\right)$ of ferrites nanoparticles has been given in Supplementary Section 1 . The $S_{\mathrm{BET}}$ for ferrites in the range of $13-23 \mathrm{~m}^{2} \mathrm{~g}^{-1}$ were found lower than those reported in the literature where ferrites were synthesized by sol-gel method ${ }^{16}$. Various parameters like $S_{\text {tot }}$, $S_{\text {BET }}$, pore volume $\left(V_{\mathrm{p}}\right)$, and pore diameter $\left(D_{\mathrm{p}}\right)$ have been tabulated in Supplementary Table 1.

Figure 2 (a) showed the X-ray diffraction (XRD) pattern of CoF, NiF, CuF, and $\mathrm{ZnF}$. The diffraction peaks of $\mathrm{CuF}$ nanoparticles at $18.3^{\circ}, 29.9^{\circ}, 35.3^{\circ}, 35.9^{\circ}, 37.1^{\circ}, 43.9^{\circ}, 54.1^{\circ}, 57.1^{\circ}, 58.0^{\circ}, 62.1^{\circ}$, and $64.0^{\circ}$ were assigned to ( $h k l)$ (101), (112), (103), (211), (202), (220), (312), (303), (321), (224), and (400) planes of tetragonal $\mathrm{CuFe}_{2} \mathrm{O}_{4}$ (JCPDS card no. $34-0425)^{19}$. The lattice parameters, $a(5.83 \AA)$ and $c(8.61 \AA)$, matched well with the literature $^{20}$. Besides, the diffraction peaks appeared for CoF, NiF, and ZnF matched with the JCPDS card no. 22-1086, $10-0325$, and 22-1012, respectively. The lattice parameter for these cubic spinel structures, $a=8.38 \AA(\mathrm{CoF})$, $8.34 \AA(\mathrm{NiF})$, and $8.45 \AA \mathrm{ZnF})$, was found consistent with the earlier reported values ${ }^{16}$. In NiF and CuF photocatalysts, $\mathrm{Fe}_{2} \mathrm{O}_{3}$ was confirmed as an impurity that was absent in $\mathrm{CoF}$ and $\mathrm{ZnF}$. The crystallite size of a ferrite nanoparticle was calculated using the Debye-Scherrer equation: $D=0.9 \lambda /(\beta \operatorname{Cos} \theta)$, where $D$ is the crystallite size, $\lambda$ is the wavelength of $\mathrm{Cu} \mathrm{K} \alpha$ radiation, $\beta$ is the full width at half maximum of the diffraction peak, and $\theta$ is the Bragg angle ${ }^{21}$. The crystallite size for $\mathrm{CoF}, \mathrm{NiF}, \mathrm{CuF}$, and $\mathrm{ZnF}$ was found to be $34 \mathrm{~nm}, 27 \mathrm{~nm}, 16 \mathrm{~nm}$, and $36 \mathrm{~nm}$, respectively (Supplementary Table 2 ).

Figure 2(b) showed the Fourier-transform infrared (FTIR) spectra of CoF, NiF, CuF, and ZnF photocatalysts. Two distinct bands for metal-oxygen vibrations were observed in the range of $750-400 \mathrm{~cm}^{-1}$ for all the four ferrite photocatalysts. The high-intensity band in the range of $750-500 \mathrm{~cm}^{-1}\left(v_{1}\right)$ was attributed to the intrinsic stretching vibrations of the tetrahedral site-occupied metal-oxygen bond $\left[\mathrm{M}^{2+}\right.$ tetra $\left.\leftrightarrow \mathrm{O}\right]$. The low-intensity band $450-400 \mathrm{~cm}^{-1}\left(v_{2}\right)$ was due to the octahedral Fe $\mathrm{Fe}^{3+}$-oxygen stretching vibration ${ }^{21}$. The broad band centered at $3427 \mathrm{~cm}^{-1}$ and a low-intensity band centered at $1630 \mathrm{~cm}^{-1}$ were assigned to the stretching and bending mode of $\mathrm{O}-\mathrm{H}$ bonds of physically adsorbed water molecules.

Ultraviolet visible diffuse reflectance spectroscopy (UV-Vis DRS) analysis was performed to evaluate the optical properties of ferrite photocatalysts, and results have been shown in Fig. 2(c). All four ferrites showed a strong 


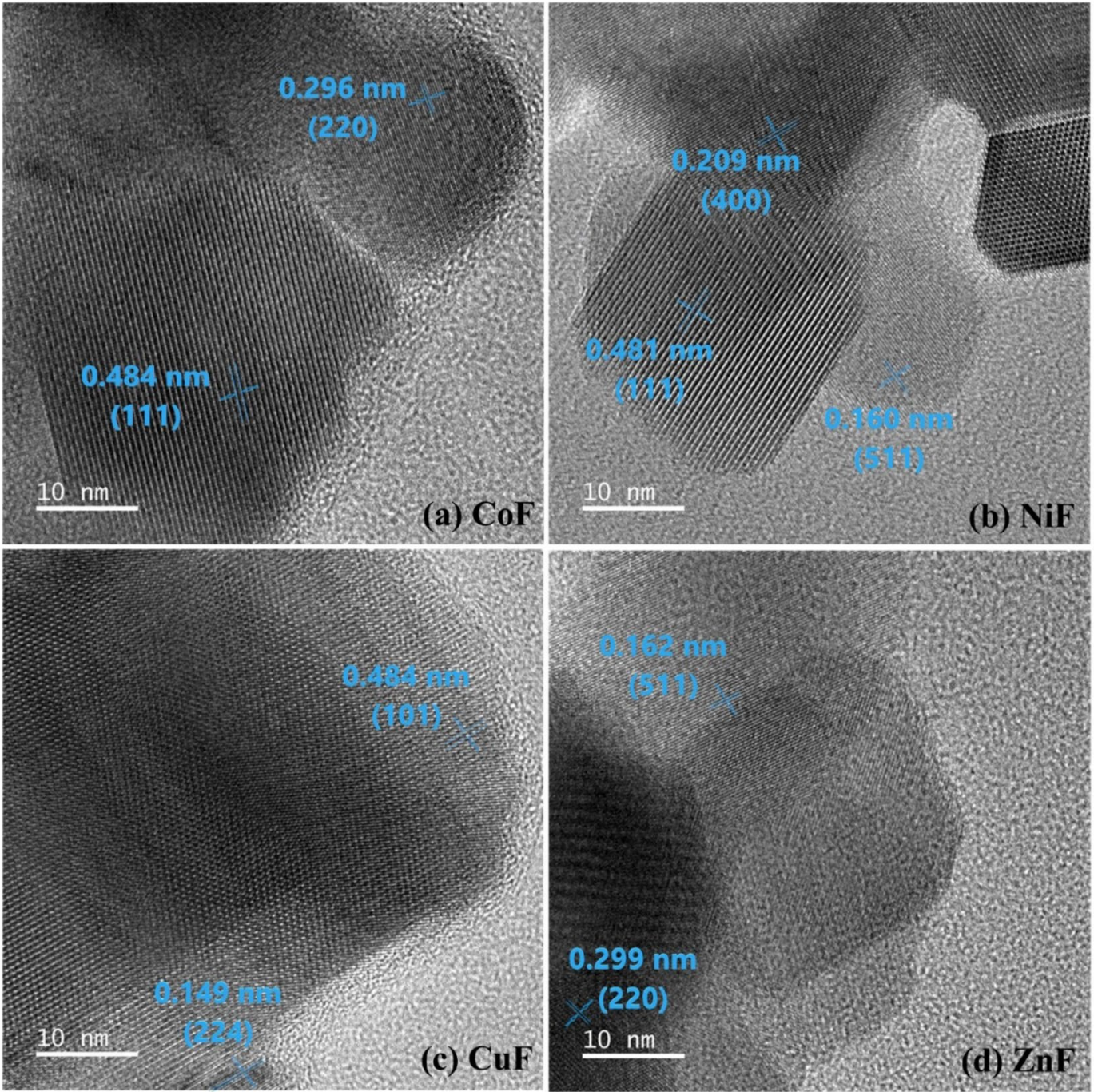

Figure 1. HRTEM images of (a) $\operatorname{CoF}(\mathbf{b}) \mathrm{NiF}(\mathbf{c}) \operatorname{CuF}(\mathrm{d}) \mathrm{ZnF}$ photocatalysts.

absorption band in the entire UV-Visible region. The optical direct band gap was calculated using the following equation $^{22}$ :

$$
(\alpha h v)^{2}=B\left(h u-E_{g}\right)
$$

where, $\alpha, v$, and $B$ are absorption coefficient, light frequency, and the proportionality constant, respectively. The $(\alpha h v)^{2}$ versus $h v$ plots for ferrite photocatalysts have been shown in Fig. 2(d). The band gap calculated for CoF, $\mathrm{NiF}, \mathrm{CuF}$, and $\mathrm{ZnF}$, i.e., $1.11 \mathrm{eV}, 1.59 \mathrm{eV}, 1.55 \mathrm{eV}$, and $1.81 \mathrm{eV}$, respectively, were found significantly lower than those reported in the literature ${ }^{16}$.

X-ray photoelectron spectroscopy (XPS) analysis was carried out to determine the elemental composition and oxidation states of ferrite photocatalysts. The XPS full scan spectra of ferrites (Fig. 3(a)) confirmed the existence of predominant constituent elements. The high-resolution XPS (HRXPS) spectra of individual elements have been deconvoluted using Fityk software. In the deconvoluted HRXPS O $1 \mathrm{~s} \mathrm{spectrum} \mathrm{(Fig.} \mathrm{3(b)),} \mathrm{two} \mathrm{peaks}$ at $529.52 \mathrm{eV}$ and $531.67 \mathrm{eV}$ were assigned to the metal-oxygen bonds (lattice oxygen) and oxygen defect sites, respectively ${ }^{23}$. The proportion of oxygen defect sites was found significantly higher for CoF photocatalyst (image not shown here). In the HRXPS Fe 2 p spectrum (Fig. 3(c)), two spin-orbit doublets Fe $2 p_{3 / 2}(709.47 \mathrm{eV}$ for B-sites and $710.55 \mathrm{eV}$ for A-sites) and $\mathrm{Fe} 2 \mathrm{p}_{1 / 2}$ (723.67 eV for B-sites and $725.86 \mathrm{eV}$ for A-sites) were observed for $\mathrm{Fe}^{3+}$ ions in the ferrite photocatalyst. The peaks at $718.42 \mathrm{eV}, 723.67 \mathrm{eV}$, and $731.87 \mathrm{eV}$ were satellite peaks ${ }^{24}$. The peak position of $\mathrm{Fe} 2 \mathrm{p}_{3 / 2}$ B-sites and $\mathrm{Fe} 2 \mathrm{p}_{1 / 2} \mathrm{~B}$-sites coincided with the peak positions of $\mathrm{Fe}^{2+}$ species ${ }^{25}$, indicating that $\mathrm{Fe}^{2+} / \mathrm{Fe}^{3+}$ ions could occupy the octahedral sites. The HRXPS Co 2p spectrum (Supplementary Fig. 6(a)) showed two peaks at $782.06 \mathrm{eV}$ and $787.53 \mathrm{eV}$, which were due to the existence of $\mathrm{Co}^{2+}$ ions ${ }^{26}$. For the HRXPS Ni 2p spectrum (Supplementary Fig. 6(b)), two spin-orbit doublets corresponding to the characteristic peaks of $\mathrm{Ni}^{2+}$ $(853.61 \mathrm{eV})$ and $\mathrm{Ni}^{3+}(855.23 \mathrm{eV})$ and two shakeup satellites $(860.44 \mathrm{eV}$ and $878.19 \mathrm{eV})$ were observed showing a peculiar existence of $\mathrm{Ni}^{3+}$ in the $\mathrm{NiF}$ photocatalyst ${ }^{27}$. Supplementary Figure 6(c) showed the binding energies of $\mathrm{Cu} 2 \mathrm{p}_{3 / 2}(933.90 \mathrm{eV})$ and $\mathrm{Cu} 2 \mathrm{p}_{1 / 2}(953.76)$ with two satellites confirming the presence of $\mathrm{Cu}^{2+}$ ions in $\mathrm{CuF}$ 

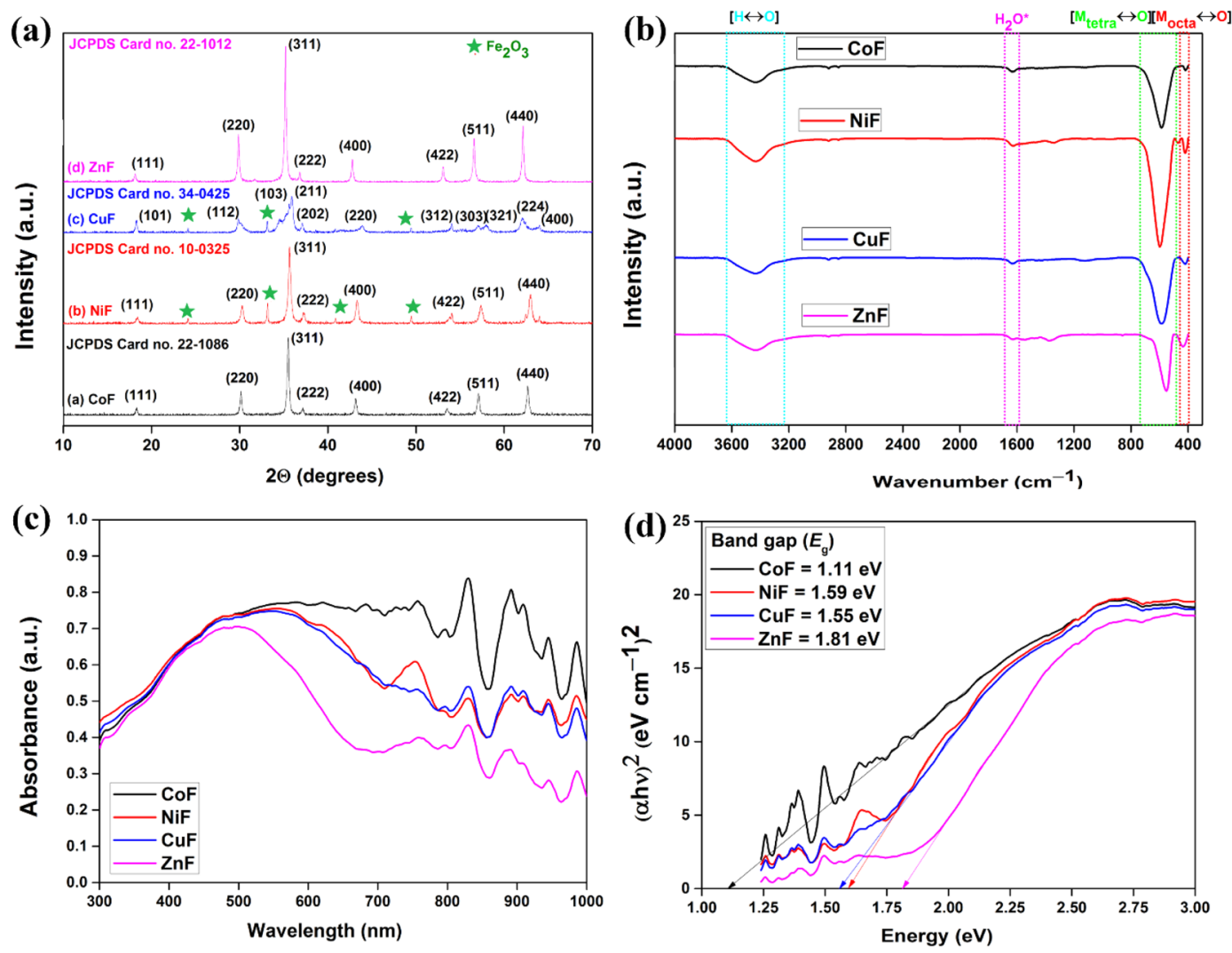

Figure 2. (a) XRD spectra; (b) FTIR spectra; (c) UV-Vis DRS spectra; (d) band gap energies of ferrites photocatalysts.

photocatalyst ${ }^{28}$. Supplementary Figure 6(d) showed two peaks at $1020.37 \mathrm{eV}$ and $1043.50 \mathrm{eV}$ for $\mathrm{Zn}^{2+}$ corresponding to $\mathrm{Zn} 2 \mathrm{p}_{3 / 2}$ and $\mathrm{Zn} 2 \mathrm{p}_{1 / 2}$, respectively for $\mathrm{ZnF}$ photocatalyst ${ }^{29}$.

The electron spin resonance (ESR) spectrum of ZnF photocatalyst has been shown in Supplementary Fig. 7. In ZnF, two systems contribute toward ESR signals: one is high spin $\mathrm{Fe}^{3+}\left(d^{5}\right)$ coordinated with oxygen, and the other is singly ionized oxygen vacancy $\left(\mathrm{V}_{\mathrm{O}}{ }^{+}\right)$. The doubly ionized $\left(\mathrm{V}_{\mathrm{O}}{ }^{+2}\right)$ and non-ionized $\left(\mathrm{V}_{\mathrm{O}}{ }^{0}\right)$ oxygen vacancies are ESR silent ${ }^{30}$. The $\mathrm{Zn}^{2+}$ ions with filled $d^{10}$ orbital do not contribute to the ESR signal. In the present case, a signal was recorded at $g=2.001$, which was assigned to $\mathrm{V}_{\mathrm{O}}{ }^{+}$. The signal at $g=2.232 \mathrm{for} \mathrm{Fe}^{3+}$ ion in the octahedral site of spinel ferrite was not observed. The signal was masked by the signal at $g=2.001$, which could be due to the effect of calcination of ferrite photocatalyst at $700^{\circ} \mathrm{C}^{31}$.

Photocatalytic activity of ferrites. The photocatalytic activity of all the four ferrites, i.e., CoF, NiF, CuF, and $\mathrm{ZnF}$, was found unsatisfactory in the absence of $\mathrm{H}_{2} \mathrm{O}_{2}$ and only $30-35 \%$ of dye was found to degrade after 60 min of UV irradiation (Fig. 4(a)). Unfortunately, the photogenerated electron-hole pairs were less effective for the process due to fast recombination. In the absence of photocatalyst, less than $8 \%$ of dye degradation was observed with $\mathrm{H}_{2} \mathrm{O}_{2}$. In the presence of $\mathrm{UV}$ and $\mathrm{H}_{2} \mathrm{O}_{2}$, nearly $10 \%$ decolorization was recorded without any photocatalyst. In the dark condition, nearly $14 \%$ of $\mathrm{MB}$ dye was adsorbed onto NiF after 5 min of agitation. Thus, it was evident that the contribution of adsorption in photocatalytic degradation of dye would be even lesser due to faster degradation kinetics. The $\mathrm{H}_{2} \mathrm{O}_{2}$-assisted photodegradation of organic dye over ferrite photocatalysts showed rapid decolorization at neutral pH. As shown in Fig. 4(b), more than $90 \%$ of MB dye was found to degrade within $75 \mathrm{~s}$ of irradiation over ferrite photocatalysts. The high-intensity peak at $664 \mathrm{~nm}$ is due to conjugation between two dimethylamine substituted aromatic rings through $\mathrm{S}$ and $\mathrm{N}$. In contrast, the low-intensity peak in the ultraviolet region $(\sim 292 \mathrm{~nm})$ appears due to the aromatic rings. From Fig. 4(d), it was evident that along with the fast decolorization of $\mathrm{MB}$ dye-containing solution (due to complete breakdown of the chromophore), the intensity of $292 \mathrm{~nm}$ peak also decreased with time without forming any new band in the UV or visible region. Thus, it was concluded that complete structural degradation of $\mathrm{MB}$ dye was possible in $\mathrm{UV}-\mathrm{C} / \mathrm{H}_{2} \mathrm{O}_{2} /$ ferrite system. The photocatalytic degradation follows the pseudo-first-order kinetic model (Eq. 3) which could be expressed mathematically as ${ }^{32}$ :

$$
\ln \left(\frac{C_{t}}{C_{0}}\right)=-k_{a p p} t
$$



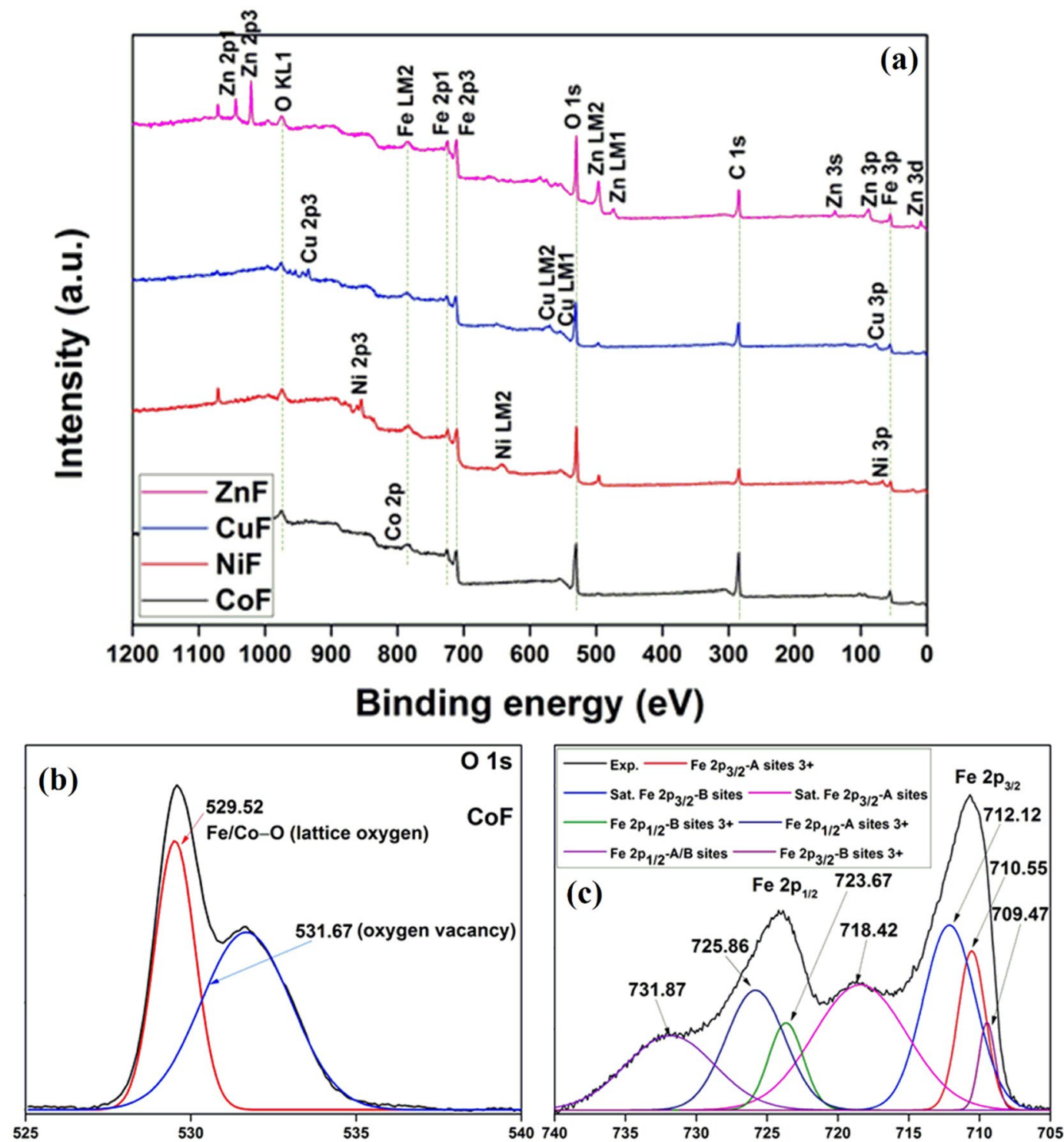

Figure 3. (a) XPS full scan; (b) HRXPS O 1s spectrum (CoF); (c) HRXPS Fe 2p spectrum (CoF).

$$
t_{1 / 2}=\frac{0.693}{k_{a p p}}
$$

where $C_{0}$ and $C_{\mathrm{t}}$ are the $\mathrm{MB}$ concentration at time $t=0$ and time ' $t$ ', respectively, and $t_{1 / 2}$ is the half-life of the dye degradation. The slope of the $\ln \left(C_{\mathrm{t}} / C_{0}\right)$ versus $t$ plot is the apparent rate constant for the reaction $\left(k_{\text {app }}\right)$. From Fig. 4(c), the calculated $k_{\text {app }}$ value was $2.141 \mathrm{~min}^{-1}, 2.417 \mathrm{~min}^{-1}, 2.065 \mathrm{~min}^{-1}$, and $2.069 \mathrm{~min}^{-1}$, for CoF, NiF, CuF, and $\mathrm{ZnF}$, respectively. The kinetic rate of degradation for ferrite photocatalysts in this study was found significantly higher than those reported in the literature ${ }^{32,33}$. The parameters evaluated from the kinetic model, along with the linear regression value, have been displayed in Supplementary Table 3.

Figure 5(a) shows the effect of photocatalyst loading on the MB degradation under the defined experimental conditions for $\mathrm{MFe}_{2} \mathrm{O}_{4}(\mathrm{M}=\mathrm{Co}, \mathrm{Ni}, \mathrm{Cu}, \mathrm{Zn})$. Increasing the photocatalyst dosage from $0.05 \mathrm{gL}^{-1}$ to $0.50 \mathrm{~g} \mathrm{~L}^{-1}$ yielded a slight increase in the \%dye degradation performance. The increased photocatalyst dosage favored the degradation process by providing more active sites for the generation of active radicals. Moreover, a small dosage of $0.05 \mathrm{~g} \mathrm{~L}^{-1}$ was found enough for $\sim 90 \%$ of $\mathrm{MB}$ degradation. Since the maximum dye degradation efficiency was recorded for $0.5 \mathrm{~g} \mathrm{~L}^{-1}$ dosage, subsequent experiments were performed with $0.5 \mathrm{~g} \mathrm{~L}^{-1}$ of the photocatalyst.

In the defined experimental conditions, high degradation efficiencies ( 92-94\%) were recorded for $10-20 \mathrm{mg} \mathrm{L}^{-1}$ solution (Fig. 5(b)). Whereas, it dropped to $\sim 65-70 \%$ for a $50 \mathrm{mg} \mathrm{L}^{-1} \mathrm{MB}$ solution. The primary reason for the result obtained was the limited production of active radicals, which were insufficient to degrade the higher concentration of MB dye $\mathrm{e}^{34}$. Also, highly concentrated MB dye solution could decrease the penetration of photons in the solution phase and thus hampered with the photogeneration of electron-hole pairs ${ }^{35}$. 

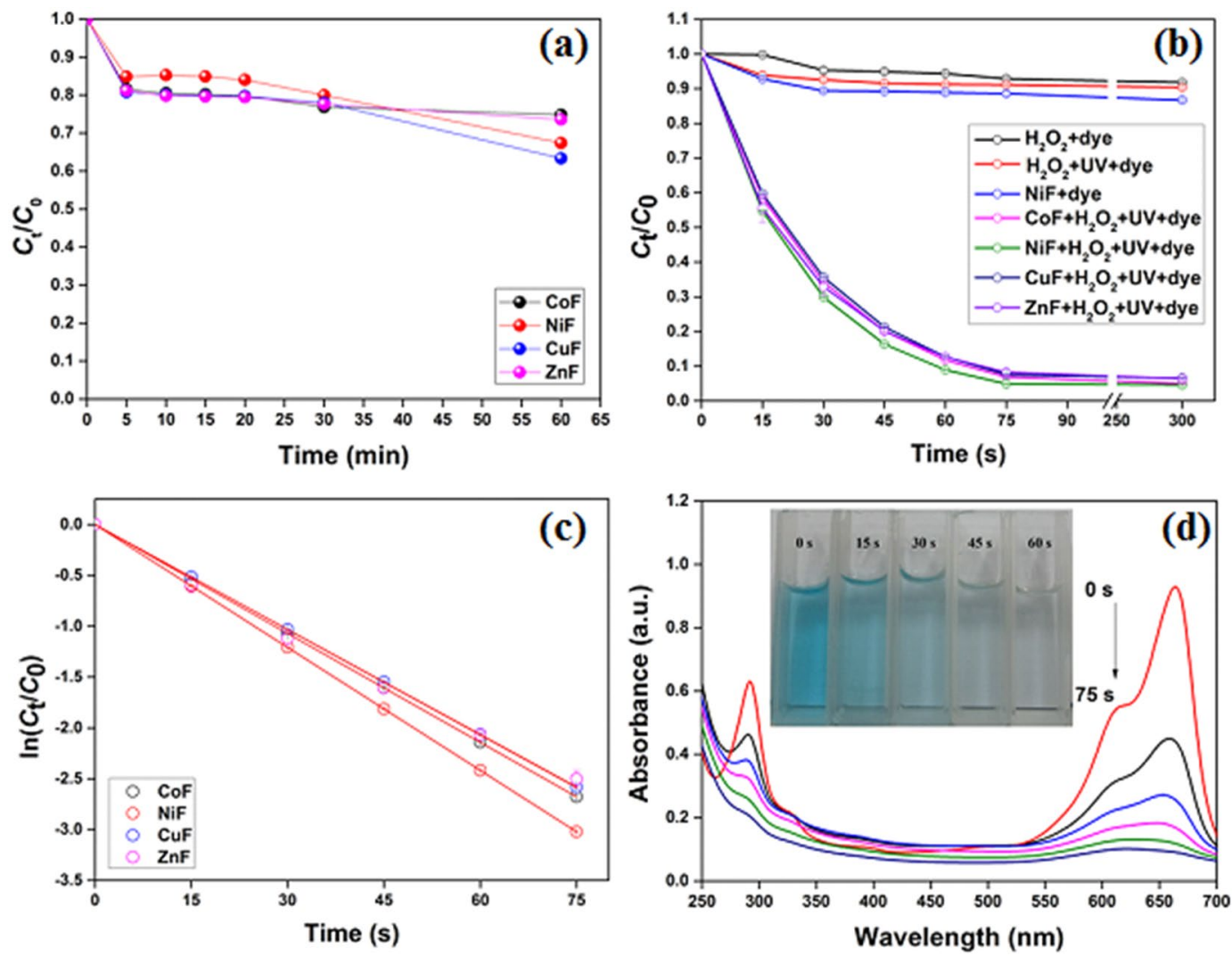

Figure 4. Degradation of MB dye over ferrite photocatalysts. (a) UV irradiation; (b) photocatalytic degradation in $\mathrm{H}_{2} \mathrm{O}_{2} / \mathrm{UV}$ system (c) plot of $\ln \left(C_{\mathrm{t}} / C_{0}\right)$ versus time $(t)$; (d) intensity change with irradiation time $(\mathrm{ZnF})$. Conditions: $[\mathrm{MB}]=10 \mathrm{mg} \mathrm{L}^{-1}$, [photocatalyst $]=0.5 \mathrm{~g} \mathrm{~L}^{-1},\left[\mathrm{H}_{2} \mathrm{O}_{2}\right]=5 \mathrm{mmol} \mathrm{L}^{-1}$.

It was observed that with the increase in the $\mathrm{H}_{2} \mathrm{O}_{2}$ concentration, the $\mathrm{MB}$ degradation efficiency decreased by $\sim 3-5 \%$ for all the photocatalysts (Fig. 5(c)). In general, an increased $\mathrm{H}_{2} \mathrm{O}_{2}$ concentration favors the process by providing $\bullet \mathrm{OH}$ radicals. Nevertheless, the increased $\mathrm{H}_{2} \mathrm{O}_{2}$ concentration disfavored the photocatalytic process due to the generation of hydroperoxyl radicals $\left(\mathrm{HOO}^{\bullet}\right)$, which exhibits lower oxidation capabilities and did not contribute to the degradation process ${ }^{16}$ (Eqs. 4 and 5). Moreover, radical-radical reactions could have competed with the radical-dye reactions and led to a decreased degradation performance ${ }^{15}$ (Eq. 6). Thus, $\mathrm{H}_{2} \mathrm{O}_{2}$ concentration of $5 \mathrm{mmol} \mathrm{L}^{-1}$ was found suitable for the dye degradation process.

$$
\begin{gathered}
\mathrm{HO}^{\circ}+\mathrm{H}_{2} \mathrm{O}_{2} \rightarrow \mathrm{H}_{2} \mathrm{O}+\mathrm{HOO}^{\circ} \\
\mathrm{HOO}^{\circ}+\mathrm{HO}^{\circ} \rightarrow \mathrm{H}_{2} \mathrm{O}+\mathrm{O}_{2} \\
\mathrm{HO}^{\circ}+\mathrm{HO}^{\circ} \rightarrow \mathrm{H}_{2} \mathrm{O}_{2}
\end{gathered}
$$

For an energy-efficient process, the power required for the dye degradation was optimized by taking the number of $8 \mathrm{~W}$ UV lamps into consideration. As shown in Fig. 5(d), more than $90 \%$ of the dye was found to degrade under one lamp of $8 \mathrm{~W}$. But with the increase in the number of lamps from two to four, the photocatalytic performance reached up to $95 \%$. An increased UV power led to the adsorption of more photons by the photocatalysts, which in turn accelerated the formation of electron-hole pairs. Considering the power-to-performance ratio, $16 \mathrm{~W}$, i.e., two $8 \mathrm{~W}$ lamps, were taken as the illumination source for subsequent studies.

TOC analysis was done to evaluate the mineralization efficiency of a ferrite photocatalyst. The \% TOC removal performance of NiF photocatalyst has been shown in Fig. 6(a). In the first $15 \mathrm{~s}$ of the degradation process, only $1.1 \%$ mineralization of organic species was observed. It increased to $40.0 \%$ and $60.2 \%$ after $5 \mathrm{~min}$ and $50 \mathrm{~min}$, respectively. Thus, it was confirmed that $\mathrm{MB}$ dye could be effectively mineralized into residual organic molecules in $\mathrm{UV} / \mathrm{H}_{2} \mathrm{O}_{2} / \mathrm{NiF}$ system.

The optimized parameters were used for the photocatalytic degradation of methyl orange (MO), bromo green (BG), and methyl red (MR) over NiF photocatalyst. Similar experiments were performed, and the photocatalytic performances have been shown in Fig. 6(b). Within 1 min of the irradiation time, nearly $91.8 \%$ of MO, 92.5\% of BG, and $77.2 \%$ of MR were degraded by NiF photocatalyst, which increased to $94.0 \%$ (MO), $93.3 \%$ (BG), and $81.8 \%$ (MR) after $5 \mathrm{~min}$. Thus, these ferrite photocatalysts in the $\mathrm{UV}-\mathrm{C} / \mathrm{H}_{2} \mathrm{O}_{2}$ system exhibited remarkable properties for rapid degradation of toxic organic dyes at neutral $\mathrm{pH}$. 

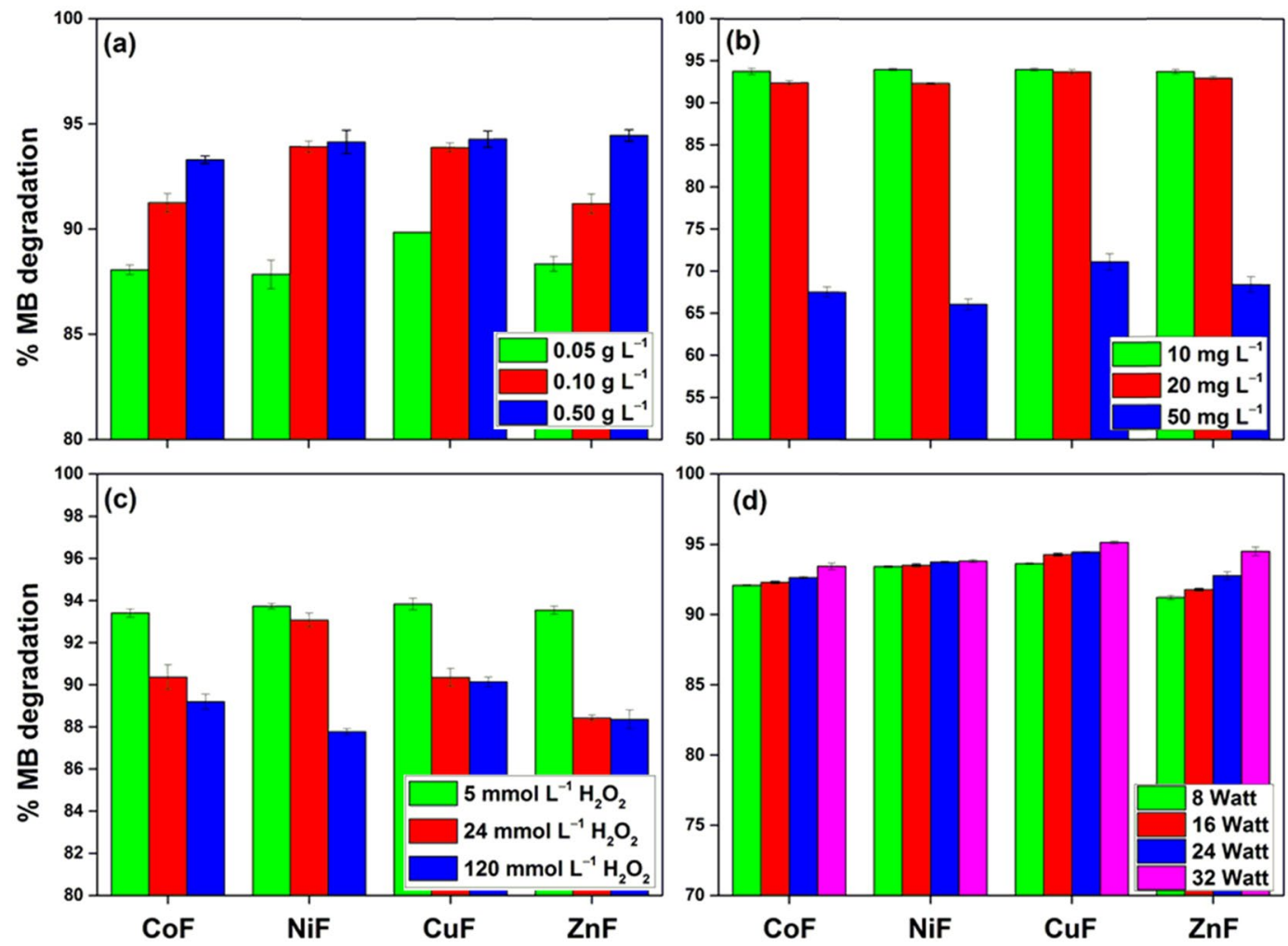

Figure 5. Effect of (a) Photocatalyst dosage; (b) Dye concentration; (c) $\mathrm{H}_{2} \mathrm{O}_{2}$ concentration; (d) UV-C power on the degradation of $\mathrm{MB}$ dye onto ferrite photocatalysts. Conditions: $[\mathrm{MB}]=10 \mathrm{mg} \mathrm{L}^{-1}$, [photocatalyst] $=$ $0.5 \mathrm{~g} \mathrm{~L}^{-1},\left[\mathrm{H}_{2} \mathrm{O}_{2}\right]=5 \mathrm{mmol} \mathrm{L}^{-1}, \mathrm{UV}-\mathrm{C}$ power $=16 \mathrm{~W}$, time $=5 \mathrm{~min}$ (changed accordingly).
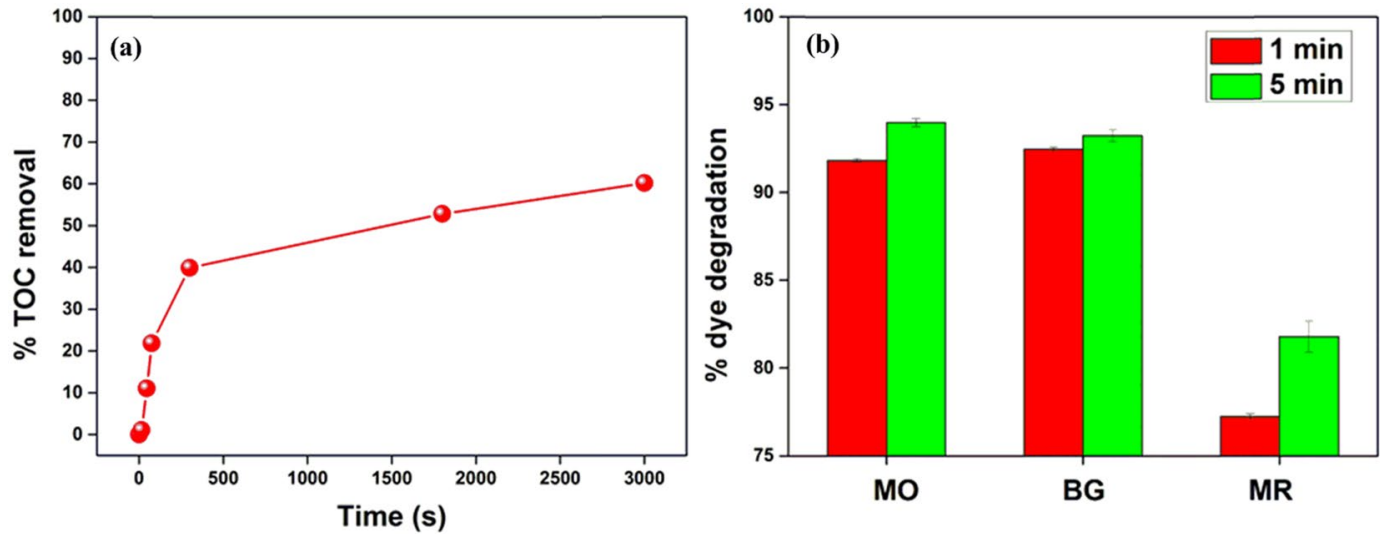

Figure 6. (a) The TOC removal efficiency of $\mathrm{MB}$ dye using NiF photocatalyst. (b) Degradation of MO, BG, and MR dyes. Conditions: $[$ Dye $]=10 \mathrm{mg} \mathrm{L}^{-1},\left[\mathrm{H}_{2} \mathrm{O}_{2}\right]=5 \mathrm{mmol} \mathrm{L}^{-1},[\mathrm{NiF}]=0.5 \mathrm{~g} \mathrm{~L}^{-1}$, UV-C power $=16 \mathrm{~W}$.

Photocatalytic degradation mechanism. Different scavenging experiments were performed to identify the main active species responsible for the photocatalytic degradation of organic dyes onto ferrite photocatalysts. EDTA, $\mathrm{K}_{2} \mathrm{Cr}_{2} \mathrm{O}_{7}$, and $p$-benzoquinone were used as a scavenger for the hole $\left(h^{+}\right)$, electron $\left(e^{-}\right)$, and superoxide anion radical $\left({ }^{\bullet} \mathrm{O}_{2}^{-}\right)$, respectively. Tert-butanol was chosen as a hydroxyl radical scavenger for all $\bullet^{\bullet} \mathrm{OH}$ generated in the reaction process, whereas $\mathrm{KI}$ was used as a surface-bound ${ }^{\bullet} \mathrm{OH}\left({ }^{\bullet} \mathrm{OH}\right.$ surf $)$ scavenger at the catalytic surface $^{36,37}$. As evident from Fig. 7(a), the degradation performance decreased in the order: tert-butanol $>\mathrm{KI}$ $>$ EDTA $>\mathrm{K}_{2} \mathrm{Cr}_{2} \mathrm{O}_{7}>$ p-benzoquinone $>$ no scavenger. Since the presence of tert-butanol severely affected the photocatalytic process, it was conclusive that the generated ${ }^{\bullet} \mathrm{OH}$ radicals were the primary active species for the degradation process. Additionally, the presence of KI lowered the degradation performance by $40 \%$ within $1 \mathrm{~min}$, suggesting that surface-bound $\left({ }^{\circ} \mathrm{OH}\right.$ surf $)$ released into the solution and took part in the dye degradation process. When ferrite photocatalyst was irradiated under UV lamps, electron/hole $\left(e^{-} / h^{+}\right)$pairs were generated on the surface (Eq. 7). The primary pathway for the generation of ${ }^{\bullet} \mathrm{OH}$ radicals was the Fenton reaction, where $\mathrm{H}_{2} \mathrm{O}_{2}$ 

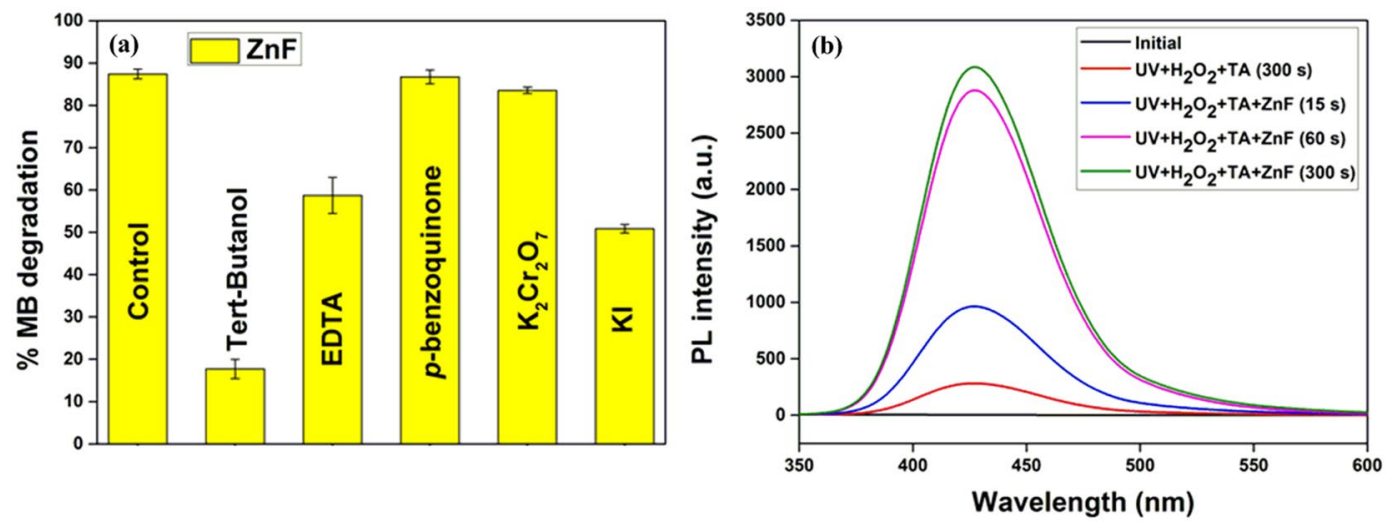

Figure 7. (a) Photocatalytic degradation of $\mathrm{MB}$ dye over $\mathrm{ZnF}$ photocatalyst in the presence of scavengers; (b) Fluorescence spectra of 2-hydroxy terephthalic acid (TAOH) $\left(\lambda_{\text {ex }} \sim 315 \mathrm{~nm}\right)$ in the presence of $\mathrm{ZnF}$.

was activated by regenerated $\mathrm{Fe}^{2+}$ (Eq. 8). The regeneration of was possible due to the reaction of $\mathrm{Fe}^{3+}$ ions with photogenerated $e^{-}\left(E^{0}\left(\mathrm{Fe}^{3+} / \mathrm{Fe}^{2+}\right)=+0.77 \mathrm{~V}\right)$ in the conduction band (Eq. 9). The dye degradation performance decreased from $\sim 89 \%$ to $\sim 54 \%$ in the presence of EDTA, suggesting the involvement of $h^{+}$(photogenerated in the valence band of $\mathrm{ZnF}$ ) directly in the degradation of $\mathrm{MB}$ dye (Eq. 12). The dye degradation process was also affected by the scavenging behavior of $\mathrm{K}_{2} \mathrm{Cr}_{2} \mathrm{O}_{7}$ and $p$-benzoquinone. The photogenerated $e^{-}$in the conduction band of $\mathrm{ZnF}$ reacted with the adsorbed $\mathrm{O}_{2}$ molecules to yield ${ }^{\circ} \mathrm{O}_{2}^{-}$(Eq. 10), which either reacted directly with the $\mathrm{MB}$ dye (Eq. 13) or further combined with $\mathrm{H}^{+}$to produce ${ }^{\bullet} \mathrm{OH}$ radicals. From the study, it was conclusive that $\bullet \mathrm{OH}$ (Eq. 11) and $h^{+}$served as the major active species, whereas electron was minor active species.

$$
\begin{gathered}
\mathrm{ZnF}+\mathrm{hv} \rightarrow \mathrm{e}_{\mathrm{CB}}^{-}+h_{V B}^{+} \\
\mathrm{Fe}^{2+}+\mathrm{H}_{2} \mathrm{O}_{2} \rightarrow \mathrm{Fe}^{3+}+\mathrm{HO}^{\circ}+\mathrm{HO}^{-} \\
\mathrm{Fe}^{3+}+e_{\mathrm{CB}}^{-} \rightarrow \mathrm{Fe}^{2+} \\
\mathrm{O}_{2}+e_{\mathrm{CB}}^{-} \rightarrow \mathrm{O}_{2}^{-\cdot} \\
\mathrm{HO}+\text { Dye } \rightarrow \mathrm{CO}_{2}+\mathrm{H}_{2} \mathrm{O}+\text { degradation products } \\
h_{V B}^{+}+\text {Dye } \rightarrow[\text { Dye }]^{*} \rightarrow \text { degradation products } \\
\mathrm{O}_{2}^{-\cdot}+\text { dye } \rightarrow \text { degradation products }
\end{gathered}
$$

The formation of ${ }^{\bullet} \mathrm{OH}$ radicals on the surface of $\mathrm{ZnF}$ photocatalyst in the $\mathrm{UV} / \mathrm{H}_{2} \mathrm{O}_{2}$ system was further probed by fluorescence spectroscopy using terephthalic acid (TA) as a probe for ${ }^{\bullet} \mathrm{OH}$ radicals. The non-fluorescent TA molecule reacts with an ${ }^{\bullet} \mathrm{OH}$ radical to form fluorescent $\mathrm{TAOH}$. The fluorescent intensity of TAOH is directly proportional to the formation of ${ }^{\bullet} \mathrm{OH}$ radicals in the photocatalytic reaction and is expected to increase with the irradiation time ${ }^{38}$. When the solution was excited at $\lambda_{\mathrm{ex}} \sim 315 \mathrm{~nm}$, the fluorescence emission was observed at $\lambda_{\text {ex }} \sim 425 \mathrm{~nm}$ for TAOH (Fig. 7(b)). Some ${ }^{\bullet} \mathrm{OH}$ radicals were generated by UV irradiation of $\mathrm{H}_{2} \mathrm{O}_{2}$ via homolytic cleavage, which translated as a low fluorescence emission in the absence of $\mathrm{ZnF}$ photocatalyst. In the presence of $\mathrm{ZnF}$, the fluorescence intensity increased with the irradiation time and reached the maximum after $5 \mathrm{~min}$. Thus, it was conclusive that the formation of $\bullet \mathrm{OH}$ radicals primarily drove the photodegradation process. A schematic illustration of the photocatalytic degradation mechanism of MB dye onto $\mathrm{ZnF}$ has been shown in Fig. 8 .

Effect of anions and reusability. The degradation of $\mathrm{MB}$ dye in a photocatalytic process is strongly influenced by the presence of anions such as $\mathrm{SO}_{4}{ }^{2-}, \mathrm{NO}_{3}{ }^{-}, \mathrm{Cl}^{-}, \mathrm{CO}_{3}{ }^{2-}$, etc. ${ }^{39}$. The effect of inorganic anions was evaluated by subjecting $\mathrm{MB}$ solution with $100 \mathrm{mg} \mathrm{L}^{-1}$ concentration of anions to the photodegradation process. The $\% \mathrm{MB}$ degradation efficiency was found to be $94.7 \%, 94.1 \%, 93.3 \%, 93.4 \%$, and $94.1 \%$ for no anion, $\mathrm{NO}_{3}{ }^{-}, \mathrm{SO}_{4}{ }^{2-}$, $\mathrm{Cl}^{-}$, and $\mathrm{CO}_{3}{ }^{2-}$, respectively (Fig. 9(a)) showing that anions have an insignificant effect on the dye degradation efficiency of $\mathrm{ZnF}$ photocatalyst. The reusability of photocatalysts is required for their practical application on an industrial scale. Here also, the photocatalytic performance of NiF photocatalyst was evaluated for seven cycles by regenerating photocatalyst only by washing and drying at $100^{\circ} \mathrm{C}$. In Fig. 9(b), NiF photocatalyst inevitably showed a higher degree of stability and photocatalytic activity towards the degradation of $\mathrm{MB}$ dye for seven consecutive runs. Nearly $6.0 \%$ loss in photodegradation efficiency was observed after the seventh cycle making these photocatalysts highly suitable for even more cycles. 


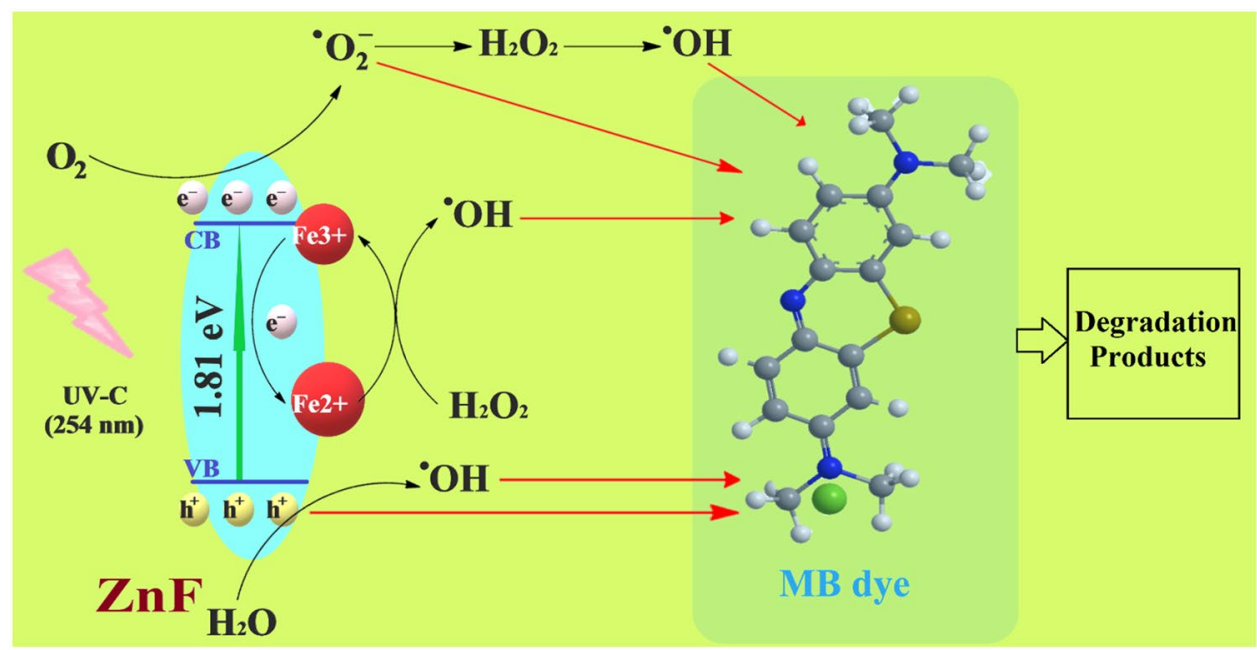

Figure 8. Schematic illustration of photocatalytic degradation process of MB dye onto ZnF photocatalyst.
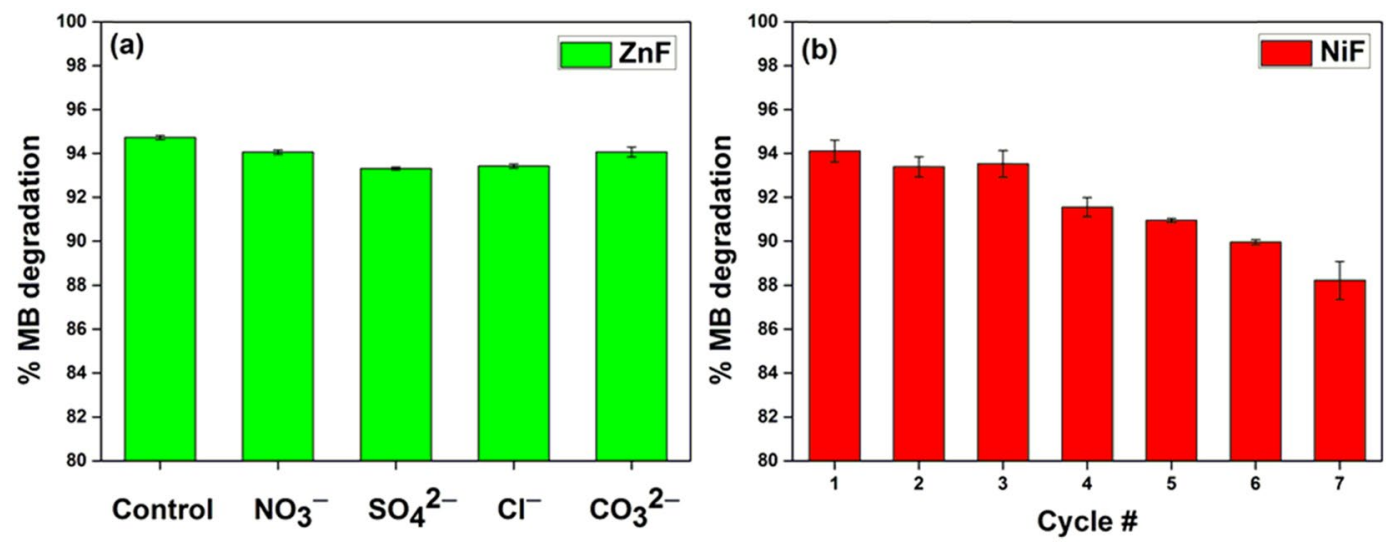

Figure 9. (a) Effect of anions on the degradation of $\mathrm{MB}$ dye onto $\mathrm{ZnF}$ photocatalyst. Conditions: [MB] $=10 \mathrm{mg} \mathrm{L}^{-1}$, [anion] $=100 \mathrm{mg} \mathrm{L}^{-1},\left[\mathrm{H}_{2} \mathrm{O}_{2}\right]=5 \mathrm{mmol} \mathrm{L}^{-1}$, [photocatalyst] $=0.5 \mathrm{~g} \mathrm{~L}^{-1}$, time $=5 \mathrm{~min} ;(\mathbf{b})$ Reusability of $\mathrm{NiF}$ photocatalyst for seven successive cycles for the degradation of $\mathrm{MB}$.

\section{Conclusions}

In this study, we have demonstrated excellent photocatalytic activity of $\mathrm{MFe}_{2} \mathrm{O}_{4}$ nanoparticles synthesized by the CTAB-mediated co-precipitation-oxidation method. The XRD and TEM analysis confirmed cubic symmetry for $\mathrm{CoF}, \mathrm{NiF}$, and $\mathrm{ZnF}$ with crystallite size in the range of $27-36 \mathrm{~nm}$. The $\mathrm{CuF}$ nanoparticles were in the tetragonal symmetry with $16 \mathrm{~nm}$ as the crystallite size. All the ferrites absorbed effectively in the UV-Vis-NIR region. The ferrites were used for the photocatalytic degradation of organic dyes in neutral $\mathrm{pH}$ conditions. In optimized experimental conditions, $\mathrm{NiF}$ showed an extraordinary rate of $2.417 \mathrm{~min}^{-1}$ for $\mathrm{MB}$ dye degradation, which decreased to $2.065 \mathrm{~min}^{-1}$ for $\mathrm{ZnF}$. The NiF photocatalyst showed $89 \%$, 92\%, 93\%, and 78\% decolorization of $\mathrm{MB}, \mathrm{MO}, \mathrm{BG}$, and $\mathrm{MR}$, respectively, in the same experimental conditions. A $40 \%$ TOC removal was observed in the first $5 \mathrm{~min}$ of the degradation process, which further increased to $60 \%$ after $50 \mathrm{~min}$. The dye degradation mechanism in the $\mathrm{UV} / \mathrm{H}_{2} \mathrm{O}_{2}$ /ferrite system was primarily driven by the formation of ${ }^{\bullet} \mathrm{OH}$ radicals and holes, which was confirmed by scavenger studies and fluorescence spectroscopy. Apart from being highly reusable, the photocatalyst showed excellent performance in the presence of a ten-fold concentration of salts. From this study, it was concluded that these photocatalysts have the potential to be used for the affordable treatment of dye-contaminated wastewater without modifying the $\mathrm{pH}$ under low power UV-C irradiation.

\section{Methods}

All the chemicals were of analytical grade and used without any further purification, whose details are available in Supplementary Section $2 . \mathrm{MFe}_{2} \mathrm{O}_{4} \mathrm{NPs}$ were synthesized by the surfactant-mediated co-precipitation method ${ }^{40}$. For the synthesis of $\mathrm{CoFe}_{2} \mathrm{O}_{4}, 4.76 \mathrm{~g}$ of $\mathrm{CoCl}_{2} \bullet 6 \mathrm{H}_{2} \mathrm{O}$ and $16.16 \mathrm{~g}$ of $\mathrm{Fe}\left(\mathrm{NO}_{3}\right)_{3} \bullet 9 \mathrm{H}_{2} \mathrm{O}$ were dissolved in $500 \mathrm{~mL}$ of distilled water at $60^{\circ} \mathrm{C}$ with constant stirring for $10 \mathrm{~min}$. To it, $1.0 \mathrm{~g}$ cetyl trimethylammonium bromide was added and vigorously stirred at $60^{\circ} \mathrm{C}$ for $30 \mathrm{~min}$. To this solution, $1.0 \mathrm{~mol} \mathrm{~L}^{-1} \mathrm{NaOH}$ solution was added until $\mathrm{pH} 12$ was achieved. After stirring for $1 \mathrm{~h}$, the precipitate was separated, washed with distilled water several times, and dried at $100^{\circ} \mathrm{C}$ for $24 \mathrm{~h}$. The dried precipitate was finely grounded before subjecting it to calcination 
for $24 \mathrm{~h}$ at $700^{\circ} \mathrm{C}$. The same protocol was adopted for the synthesis of $\mathrm{NiFe}_{2} \mathrm{O}_{4}, \mathrm{CuFe}_{2} \mathrm{O}_{4}$, and $\mathrm{ZnFe}_{2} \mathrm{O}_{4}$ using $4.75 \mathrm{~g}$ of $\mathrm{NiCl}_{2} \bullet 6 \mathrm{H}_{2} \mathrm{O}, 4.99 \mathrm{~g}$ of $\mathrm{CuSO}_{4} \bullet 5 \mathrm{H}_{2} \mathrm{O}$, and $5.95 \mathrm{~g}$ of $\mathrm{Zn}\left(\mathrm{NO}_{3}\right)_{2} \bullet 6 \mathrm{H}_{2} \mathrm{O}$, respectively along with $16.16 \mathrm{~g}$ of $\mathrm{Fe}\left(\mathrm{NO}_{3}\right)_{3} \bullet 9 \mathrm{H}_{2} \mathrm{O}$. As-synthesized ferrites, $\mathrm{CoFe} \mathrm{O}_{4}, \mathrm{NiFe}_{2} \mathrm{O}_{4}, \mathrm{CuFe}_{2} \mathrm{O}_{4}$, and $\mathrm{ZnFe}_{2} \mathrm{O}_{4}$, were abbreviated as CoF, $\mathrm{NiF}, \mathrm{CuF}$, and $\mathrm{ZnF}$, respectively.

The synthesized ferrites were characterized by various microscopic and spectroscopic techniques whose details are available in Supplementary Section 3. The photocatalytic performance of synthesized ferrites nanoparticles was evaluated by degrading $\mathrm{MB}$ dye in an acryl reactor with four UV lamps $\left(8 \mathrm{~W}, I_{\max } \sim 254 \mathrm{~nm}\right.$, Philips, The Netherlands) installed in a rectangular assembly. All the experiments were performed at $20 \pm 2{ }^{\circ} \mathrm{C}$ (temperature was maintained by cooling fans attached at the bottom of the reactor) and at a near-neutral $\mathrm{pH}$ condition. For the photodegradation study, $100 \mathrm{mg}$ of a ferrite photocatalyst along with $200 \mathrm{~mL}$ of $\mathrm{MB}$ solution $\left(10 \mathrm{mg} \mathrm{L}^{-1}\right)$ was taken in a $250 \mathrm{~mL}$ pyrex glass tube and subjected to UV-irradiation. After the desired contact time, $5 \mathrm{~mL}$ of the aqueous phase was taken out with a disposable syringe filter (Hyundai micro, Model: SN25P045NS) having a microfiltration membrane (pore size: $0.45 \mu \mathrm{m}$ ) to lock the photocatalyst. The locked photocatalyst was pumped back into the aqueous solution by pumping $2 \mathrm{~mL}$ of the aqueous phase through the syringe. The remaining $3 \mathrm{~mL}$ of the sample solution was analyzed by UV-Vis spectroscopy (LAMBDA 365 UV/Vis Spectrophotometer, Perkin Elmer) after suitable dilution. For photocatalytic degradation process, the same protocol as stated above was followed where $0.1 \mathrm{~mL}$ of $28 \% \mathrm{H}_{2} \mathrm{O}_{2}$ solution was added and samples were collected at $15 \mathrm{~s}, 30 \mathrm{~s}, 45 \mathrm{~s}, 60 \mathrm{~s}, 75 \mathrm{~s}$, and $300 \mathrm{~s}$. Similar protocol was adopted for parameter optimization study of photocatalyst loading, dye concentration, $\mathrm{H}_{2} \mathrm{O}_{2}$ concentration, and UV power as well as for different dye degradation study. For the detection of active species in the photocatalytic process, $2 \mathrm{~mL}$ of scavenger solution (tert-butanol, EDTA, $\mathrm{K}_{2} \mathrm{Cr}_{2} \mathrm{O}_{7}$, $p$-benzoquinone, or KI) was added into the aqueous phase. The effect of anion on the MB degradation was studied by taking $100 \mathrm{mg} \mathrm{L}^{-1}$ of $\mathrm{NO}_{3}{ }^{-}, \mathrm{SO}_{4}{ }^{2-}, \mathrm{Cl}^{-}$, or $\mathrm{CO}_{3}{ }^{2-}$ anion in the above experiment process. For reusability study, the catalytic efficiency was measured for every cycle using the same protocol where the spent photocatalyst was separated, washed thrice with distilled water, dried in an oven at $100^{\circ} \mathrm{C}$, and used for the next catalytic cycle. The dye degradation efficiency was calculated using Eq. 14.

$$
\% \text { dye degradation }=\left(\frac{C_{0}-C_{t}}{C_{0}}\right) \times 100
$$

where $C_{0}$ and $C_{\mathrm{t}}$ are the initial dye concentration and dye concentration at a time ' $t$ ', respectively. All the experiments were carried out using three replicate measurements, and the standard deviation associated with data was found to be less than 5\%. The data presented in figures are the average of three values, and the bar represents the standard error of the mean value.

Received: 13 November 2019; Accepted: 5 March 2020;

Published online: 18 March 2020

\section{References}

1. Bharagava, R. N. Recent advances in environmental management. First edition. edn, (2019).

2. Mondal, S. Advances in dye removal technologies. (Springer Berlin Heidelberg, 2017).

3. Tsuboy, M. S. et al. Genotoxic, mutagenic and cytotoxic effects of the commercial dye CI Disperse Blue 291 in the human hepatic cell line HepG2. Toxicol. In. Vitro 21, 1650-1655 (2007).

4. Chung, K. T. Azo dyes and human health: A review. J. Environ. Sci. Health. C Environ. Carcinog. Ecotoxicol. Rev. 34, 233-261 (2016).

5. Das, S., Dash, S. K. \& Parida, K. M. Kinetics, isotherm, and thermodynamic study for ultrafast adsorption of azo dye by an efficient sorbent: Ternary Mg/(Al + Fe) layered double hydroxides. ACS Omega 3, 2532-2545 (2018).

6. Ojemaye, M. O. \& Okoh, A. I. Multiple nitrogen functionalized magnetic nanoparticles as an efficient adsorbent: synthesis, kinetics, isotherm and thermodynamic studies for the removal of rhodamine B from aqueous solution. Sci. Reports 9, 9672 (2019).

7. Zhu, M. X., Lee, L., Wang, H. H. \& Wang, Z. Removal of an anionic dye by adsorption/precipitation processes using alkaline white mud. J. Hazard. Mater. 149, 735-741 (2007).

8. Sen, S. K., Raut, S., Bandyopadhyay, P. \& Raut, S. Fungal decolouration and degradation of azo dyes: A review. Fungal Biol. Rev. 30, 112-133 (2016).

9. Sharma, A., Ahmad, J. \& Flora, S. J. S. Application of advanced oxidation processes and toxicity assessment of transformation products. Environ. res. 167, 223-233 (2018)

10. Minella, M. et al. Photo-Fenton oxidation of phenol with magnetite as iron source. Appl. Catal., B 154-155, 102-109 (2014).

11. Qiang, Z., Chang, J.-H. \& Huang, C.-P. Electrochemical regeneration of Fe2+ in Fenton oxidation processes. Water Res. 37, 1308-1319 (2003).

12. Diya'uddeen Basheer, H., Aziz, A. R. A. \& Daud, W. M. A. W. On the limitation of Fenton oxidation operational parameters: A review. Int. J. Chem. React. Eng. 10 (2012).

13. Garg, V. K., Sharma, V. K. \& Kuzmann, E. in Ferrites and Ferrates: Chemistry and applications in sustainable energy and environmental remediation. ACS Symposium Series. 5, 137-143 (2016).

14. Pereira, C. et al. Superparamagnetic MFe2O4 ( $\mathrm{M}=\mathrm{Fe}, \mathrm{Co}, \mathrm{Mn})$ nanoparticles: Tuning the particle size and magnetic properties through a novel one-step coprecipitation route. Chem. Mater. 24, 1496-1504 (2012).

15. Cai, C. et al. Visible light-assisted heterogeneous Fenton with ZnFe2O4 for the degradation of Orange II in water. Appl. Catal., B 182, 456-468 (2016)

16. Sharma, R., Bansal, S. \& Singhal, S. Tailoring the photo-Fenton activity of spinel ferrites (MFe2O4) by incorporating different cations $(\mathrm{M}=\mathrm{Cu}, \mathrm{Zn}, \mathrm{Ni}$ and $\mathrm{Co})$ in the structure. RSC Adv. 5, 6006-6018 (2015).

17. Dhiman, M., Goyal, A., Kumar, V. \& Singhal, S. Designing different morphologies of NiFe2O4 for tuning of structural, optical and magnetic properties for catalytic advancements. New J. Chem. 40, 10418-10431 (2016).

18. Maleki, A., Hajizadeh, Z. \& Salehi, P. Mesoporous halloysite nanotubes modified by CuFe2O4 spinel ferrite nanoparticles and study of its application as a novel and efficient heterogeneous catalyst in the synthesis of pyrazolopyridine derivatives. Sci. Reports 9,5552 (2019).

19. Hou, H., Xu, G., Tan, S. \& Xiang, S. Effects of solvents on the synthesis and infrared radiation emissivity of CuFe2O4 spinels. J. Alloys Compd. 763, 736-741 (2018). 
20. Balagurov, A. M., Bobrikov, I. A., Pomjakushin, V. Y., Sheptyakov, D. V. \& Yushankhai, V. Y. Interplay between structural and magnetic phase transitions in copper ferrite studied with high-resolution neutron diffraction. J. Magn. Magn. Mater. 374, 591-599 (2015).

21. Fareghi-Alamdari, R., Zandi, F. \& Keshavarz, M. H. Copper-cobalt synergy in $\mathrm{Cu} 1-\mathrm{xCoxFe} 2 \mathrm{O} 4$ spinel ferrite as a highly efficient and regioselective nanocatalyst for the synthesis of 2,4-dinitrotoluene. RSC Adv. 5, 71911-71921 (2015).

22. Yu, C. et al. One-pot fabrication of $\beta$-Bi2O3@Bi2S3 hierarchical hollow spheres with advanced sunlight photocatalytic RhB oxidation and $\mathrm{Cr}(\mathrm{VI})$ reduction activities. Appl. Surf. Sci. 455, 8-17 (2018).

23. Wu, L. et al. Direct growth of $\mathrm{CoFe} 2$ alloy strongly coupling and oxygen-vacancy-rich CoFe2O4 porous hollow nanofibers: an efficient electrocatalyst for oxygen evolution reaction. Energy. Technology 6, 2350-2357 (2018).

24. Magno de Lima Alves, T. et al. Wasp-waisted behavior in magnetic hysteresis curves of $\mathrm{CoFe} 2 \mathrm{O} 4$ nanopowder at a low temperature: experimental evidence and theoretical approach. RSC Adv. 7, 22187-22196 (2017).

25. Nandan, R., Gautam, A. \& Nanda, K. K. Anthocephalus cadamba shaped FeNi encapsulated carbon nanostructures for metal-air batteries as a resilient bifunctional oxygen electrocatalyst. J. Mater. Chem. A 6, 20411-20420 (2018).

26. Nappini, S. et al. Surface Charge and Coating of $\mathrm{CoFe} 2 \mathrm{O} 4$ Nanoparticles: Evidence of preserved magnetic and electronic properties. J. Phys. Chem. C 119, 25529-25541 (2015).

27. Zheng, X. et al. Controllable synthesis of NixSe $(0.5 \leq \mathrm{x}<1)$ nanocrystals for efficient rechargeable Zinc-Air batteries and water splitting. ACS Appl. Mater. Interfaces 10, 13675-13684 (2018).

28. Dong, S. et al. Crystal structure and photocatalytic properties of perovskite $\mathrm{MSn}(\mathrm{OH}) 6(\mathrm{M}=\mathrm{Cu}$ and $\mathrm{Zn})$ composites with $\mathrm{d} 10-\mathrm{d} 10$ configuration. Appl. Surf. Sci. 463, 659-667 (2019).

29. Li, L. et al. Uniformly Dispersed $\mathrm{ZnFe} 2 \mathrm{O} 4$ nanoparticles on Nitrogen-modified graphene for high-performance supercapacitor as electrode. Sci. Reports 7, 43116 (2017).

30. Sarkar, A. \& Khan, G. G. The formation and detection techniques of oxygen vacancies in titanium oxide-based nanostructures. Nanoscale 11, 3414-3444 (2019).

31. Li, Y. et al. Structural disorder controlled oxygen vacancy and photocatalytic activity of spinel-type minerals: A case study of ZnFe2O4. Chem. Geol. 504, 276-287 (2019).

32. Saha, M., Mukherjee, S., Kumar, S., Dey, S. \& Gayen, A. Albumin matrix assisted wet chemical synthesis of nanocrystalline $\mathrm{MFe} 2 \mathrm{O} 4$ $(\mathrm{M}=\mathrm{Cu}, \mathrm{Co}$ and $\mathrm{Zn})$ ferrites for visible light driven degradation of methylene blue by hydrogen peroxide. RSC Adv. 6, 58125-58136 (2016).

33. Wei, F., Wang, H., Ran, W., Liu, T. \& Liu, X. Preparation of S-N co-doped CoFe2O4@rGO@TiO2 nanoparticles and their superior UV-Vis light photocatalytic activities. RSC Adv. 9, 6152-6162 (2019).

34. Yu, C. et al. Preparation and characterization of sphere-shaped BiVO4/reduced graphene oxide photocatalyst for an augmented natural sunlight photocatalytic activity. Journal of Alloys and Compounds 677, 219-227 (2016).

35. Parvizi, E. et al. Photocatalytic efficacy of supported tetrazine on MgZnO nanoparticles for the heterogeneous photodegradation of methylene blue and ciprofloxacin. RSC Adv. 9, 23818-23831 (2019).

36. Lin, X. H., Miao, Y. \& Li, S. F. Y. Location of photocatalytic oxidation processes on anatase titanium dioxide. Catal. Sci. Technol. 7, 441-451 (2017).

37. Dong, S. et al. Fabrication of 3D ultra-light graphene aerogel/Bi2WO6 composite with excellent photocatalytic performance: A promising photocatalysts for water purification. J. Taiwan Inst. Chem. Eng. 97, 288-296 (2019).

38. Kaviya, S. \& Prasad, E. Eco-friendly synthesis of $\mathrm{ZnO}$ nanopencils in aqueous medium: a study of photocatalytic degradation of methylene blue under direct sunlight. RSC Adv. 6, 33821-33827 (2016).

39. Bouasla, C., Samar, M. E.-H. \& Ismail, F. Degradation of methyl violet 6B dye by the Fenton process. Desalination 254, 35-41 (2010).

40. Gupta, N. K., Ghaffari, Y., Bae, J. \& Kim, K. S. Synthesis of coral-like $\alpha-\mathrm{Fe} 2 \mathrm{O} 3$ nanoparticles for dye degradation at neutral pH. J. Mol. Liq., https://doi.org/10.1016/j.molliq.2020.112473. (2020).

\section{Acknowledgements}

Authors are grateful for the funds [Project \# 20190151-001] provided by the "Korea Institute of Civil Engineering and Building Technology" (KICT), Rep. of Korea.

\section{Author contributions}

N.K.G was solely responsible for material synthesis and designing of the experiments. Y.G. and M.S. carried out experiments. N.K.G. and S.K. were responsible for material characterization. J.B. and K.S.K. acquired funds and supervised the work. N.K.G. did the data analysis and prepared the manuscript.

\section{Competing interests}

The authors declare no competing interests.

\section{Additional information}

Supplementary information is available for this paper at https://doi.org/10.1038/s41598-020-61930-2.

Correspondence and requests for materials should be addressed to K.S.K.

Reprints and permissions information is available at www.nature.com/reprints.

Publisher's note Springer Nature remains neutral with regard to jurisdictional claims in published maps and institutional affiliations.

Open Access This article is licensed under a Creative Commons Attribution 4.0 International License, which permits use, sharing, adaptation, distribution and reproduction in any medium or format, as long as you give appropriate credit to the original author(s) and the source, provide a link to the Creative Commons license, and indicate if changes were made. The images or other third party material in this article are included in the article's Creative Commons license, unless indicated otherwise in a credit line to the material. If material is not included in the article's Creative Commons license and your intended use is not permitted by statutory regulation or exceeds the permitted use, you will need to obtain permission directly from the copyright holder. To view a copy of this license, visit http://creativecommons.org/licenses/by/4.0/.

(c) The Author(s) 2020 